\title{
Diagnóstico situacional de las internas del establecimiento penitenciario de Concepción
}

\author{
Situational diagnosis of Concepción penitentiary establishment prisoners
}

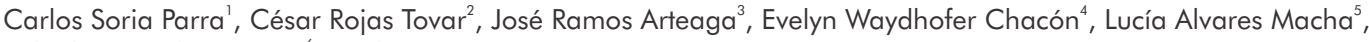
Lisbeth Gonzales Bujaico, et al.

Policia Nacional del Perú - Huancayo

\section{INTRODUCCIÓN}

El sistema penitenciario en el país está a cargo del Instituto Nacional Penitenciario (INPE), que administra un total de 66 establecimientos, organizados en ocho Oficinas Regionales (OR). De acuerdo con el artículo 139 la Constitución Política, este organismo público descentralizado del Ministerio de Justicia y Derechos Humanos tiene, como ente rector del sistema penitenciario nacional, la responsabilidad de hacer que los internos ocupen establecimientos adecuados (inciso 21) y que alcancen la reeducación, rehabilitación y reincorporación a la sociedad (inciso 22). Ambas responsabilidades, sin embargo, son claramente incumplidas. Las cárceles padecen hoy de sobrepoblación y hacinamiento sorprendentes, y es más, de condiciones adecuadas para impulsar seriamente el complejo proceso de reeducación, rehabilitación y reincorporación. Lo peor es que la sobrepoblación ya se hace incontrolable. El último año, de junio del 2011 a junio del 2012, la población de internos, según informe del INPE, llegó a 58 019, y alcanzó un asombroso crecimiento de 19,4\%, es decir, 9433 presos más (1). Las razones de todo este problema, sin duda, son tan diversas, que inclusive van más allá de las decisiones del propio organismo.

Es conocido que esta situación es dramática en las cárceles de Lima y Callao, pero no deja de ser preocupante en el interior del país. Los autores - la mayoría - estando desempeñandonos en la Policía Nacional del Perú y siendo a la vez estudiantes de

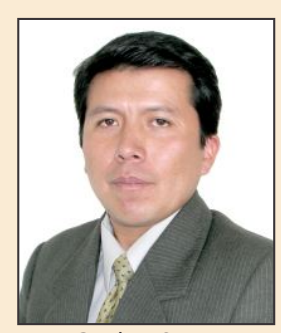

Carlos Soria

Derecho, quisimos conocer esta realidad en las cárceles en Huancayo, conformantes de la Oficina Regional Centro, y por está razón se comprometió en apoyar a las internas a través de un proceso de asesoría legal, previo estudio sobre la situación del Establecimiento Penitenciario de Mujeres de Concepción, una de la ocho cárceles de mujeres existentes en el país y la única en la zona centro. Su capacidad de albergue es para 55 internas. Está ubicada en la provincia de Concepción, a 21 kilómetros de la ciudad de Huancayo, región Junín, y funciona desde 1998, hoy regida por la directora Irma Pretell Santillana.

Esta investigación, realizada entre febrero y junio del presente año, tuvo la finalidad de elaborar un

1 Estudiantes de Derecho de la Universidad Continental. 
diagnóstico de la situación de las internas del referido establecimiento para contribuir en las decisiones orientadas a impulsar el proceso de reeducación, rehabilitación y reincorporación de estas personas a la sociedad, como fin de la pena. En este diagnóstico, identificamos aspectos relacionados al nivel educativo, estado de salud y la situación legal de las internas, entre otros, porque consideramos que se trata de información fundamental para asumir decisiones en bien de dicho proceso, que nos interesa fomentar su cumplimiento como estudiantes de Derecho.

Y es que toda pena que se limita a la simple sanción o castigo, resulta injusta y atentatoria contra los derechos humanos. Como lo establece el Código Penal, consideramos que la pena tiene la función preventiva, protectora y resocializadora (2). La pena es definida como una sanción que produce la pérdida o restricción de derechos personales, contemplada en la ley e impuesta por el órgano jurisdiccional, mediante un proceso, al individuo responsable de la comisión de un delito (3). Es impuesta en función a la gravedad del delito. La pena privativa de la libertad, como pena mayor, aún sigue siendo la más adecuada en nuestro país. Por eso, la Comisión Revisora del Código Penal, a pesar de reconocer la potencia criminógena de la prisión, considera que la pena privativa de la libertad mantiene todavía su actualidad como respuesta para los delitos que son incuestionablemente graves (2).

Sin embargo, la pena no solo debe responder a una simple sanción, sino además perseguir fines que a la postre ayuden a los penados a un cambio, mediante la reeducación, rehabilitación y reincorporación social, que es el objeto de la ejecución penal, tal como lo reafirma también el propio Código de Ejecución Penal (4).

Este trato humano es respaldado asimismo por la normatividad internacional en materia de derechos humanos que nuestro país ha suscrito ante las Naciones Unidas y que hoy tiene rango constitucional y por lo tanto es de cumplimiento obligatorio (5); también, el Pacto Internacional de Derechos Civiles y Políticos, que uno de los convenios fundamentales, defiende el trato digno a las internos y alienta a que el régimen penitenciario promueva la "reforma y readaptación social" del mismo (6).

Por esta razón, el presente estudio es muy útil. La investigación, no obstante, fue ardua. Establecimos coordinación permanente con los directivos del mencionado establecimiento, mediante cartas, para acceder a las instalaciones. Visitamos a la internas y levantamos la información del caso de manera directa y personalizada. Para ello, aplicamos un cuestionario estructurado con el fin de obtener datos sobre la situación socioeconómica, de salud y situación legal de las Internas del penal de Concepción, que nos permitió registrar valiosa información y que a continuación destacamos.

\section{Resultados del análisis}

\section{Por lugar de procedencia:}

El establecimiento tiene una población de 50 internas. El $76 \%$ de esta población (38 internas) procede del departamento de Junín y la mayoría de ellas, el $44 \%$, son de la provincia de Huancayo (22 internas). Casi la totalidad procede de los departamentos de la zona central del país (Junín, Pasco, Huánuco, Huancavelica, Ayacucho). Sin embargo, hay internas que proceden de otros lugares (Lima, Arequipa, Pucallpa, Ancash).

\section{Por tipo de delitos:}

Por tráfico ilícito de drogas, $40 \% \quad$ (20 internas); parricidio, $14 \%$; homicidio y robo agravado, 10\% cada uno. Entre los demás delitos están proxenetismo, estafa, asociación ilícita para delinquir entre otros.

Por su situación legal:

$62 \%$ de internas se encuentra con sentencia, mientras que más del tercio de la población 
$38 \%$ está en condición de procesada.

\section{Por grupos etarios:}

Más de la tercera parte también está constituida por una población joven, 34\%, que va de 18 a 30 años; $66 \%$ se encuentran en edad plenamente productiva, entre 21 y 40 años; y el $24 \%$ está entre 41 y 50 años; y el $8 \%$ supera los 50 años.

\section{Por estado civil:}

El $56 \%$ de las presidiarias son solteras; $24 \%$ convivientes; $12 \%$ están casadas. Las demás son viudas $(6 \%)$ y divorciadas $(2 \%)$.

\section{Por número de hijos:}

$75 \%$ de las internas son madres y el $25 \%$ aún no tienen hijos.

\section{Por grado de instrucción:}

$32 \%$ de las internas solo cuentan con educación primaria; $43 \%$ secundaria y el $6 \%$ carece de instrucción. Las demás tienen instrucción técnica $11 \%$ y en menor porcentaje con nivel universitario (8\%).

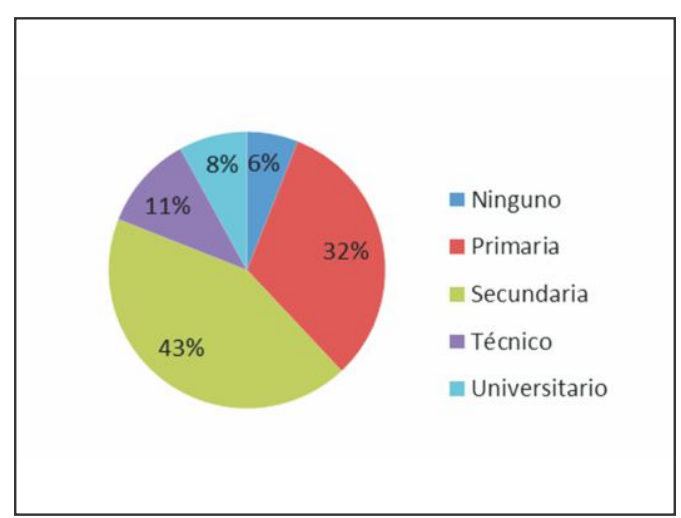

Figura 01. Distribución por grado de instrucción.

Por estado de salud:

La mitad de la población está enferma. De esta, el $46 \%$ se encuentra con algún tipo de atención, mientras que el $4 \%$ carece de esta.

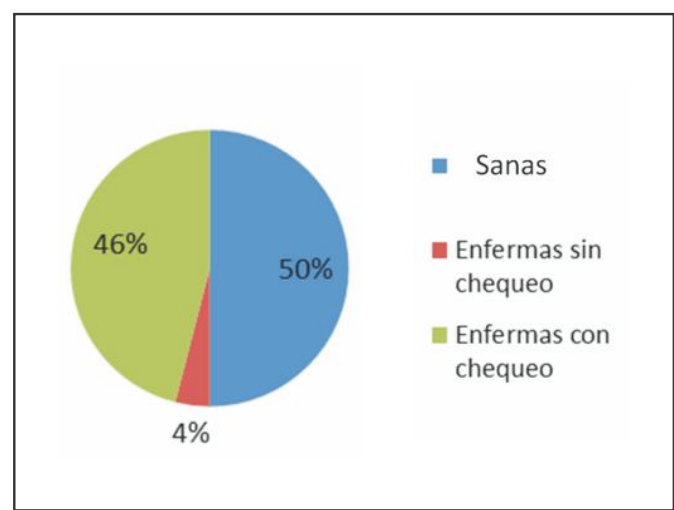

Figura 02. Distribución por el estado de salud.

De la infraestructura:

El establecimiento, si bien no tiene sobrepoblación, carece de infraestructura adecuada. Sus instalaciones, que abarcan dos pisos comprenden, en la primera planta, un pequeño patio y los dos únicos pabellones de las internas; y en la segunda, solo el área administrativa y un pequeño taller. No tiene espacios adecuados para el desarrollo de la actividad educativa, para la instalación de talleres ocupacionales, por citar solo algunas condiciones elementales. Es decir, carece de condiciones básicas para materializar el proceso de resocialización en las internas.

De acuerdo con el Reglamento de Organización y funciones del INPE, los establecimientos según su población son clasificados en A, B, C y D. Son de tipo A, los grandes penales con una población mayor a 1200 internos; de tipo B, los que tienen entre 900 y 1119 ; de tipo $C$, los que poseen entre 200 y 899 ; y los de tipo D, los que cuentan con menos de 119 internos (8). Esta clasificación, sin embargo, no precisa las características de infraestructura por cada nivel, caso que debe darse.

\section{CONCLUSIÓN}

La mayor parte de las internas proceden de la provincia de Huancayo, siendo el delito que tiene mayor recurrencia el tráfico ilícito 
de drogas, del total de los casos la mayoria tiene sentencias, también un alto porcentaje de las internas se encuentra en edad plenamente productiva y son solteras. Asimismo, la mayoria de las internas tienen hijos y su nivel educativo del $75 \%$ es de primaria o secundaria; $y$ respecto a la salud la mitad tiene alguna enfermedad.

La situación por la que atraviesa este penal constituye el reflejo del grave problema penitenciario del país, con escasos presupuestos y sin una efectiva política nacional penitenciaria. Bajo estas condiciones el proceso de reeducación, rehabilitación y reincorporación que es dificil de lograrlo.

Las autoridades del INPE y el Gobierno incumplen no solo la normatividad nacional en la respectiva materia, sino también los diversos convenios internacionales suscritos en este campo y, en general, en materia de derechos humanos. También incumplen todo lo que el sistema penitenciario acoge de las disposiciones, conclusiones y recomendaciones que Naciones Unidas establece para la prevención del delito y tratamiento del delincuente, compromiso asumido en el Código de Ejecución Penal, el Pacto Internacional de Derechos Civiles y Políticos, y las Reglas de Bangkok, instrumentos básicos que debe empezar a cumplirse.

\section{Agradecimientos}

A la ex directora de este establecimiento, Jessica Liz Aliaga Melgar, así como a la asistenta social del mismo centro, Lic. Melina Meza Rojas. También a todos los funcionarios del INPE que laboran en dicho penal, y de manera especial a cada una de las internas por su incondicional y valioso aporte que coadyuvaron al presente trabajo.

\section{REFERENCIAS BIBLIOGRÁFICAS}

1. Arauco MB, Lujan M, Farfan Y, Apolinario C, Ugarte R. Informe Estadístico [Internet]. Lima: Instituto Nacional Penitenciario; 2012 [Citado 14/07/12]. Disponible en: http://www.inpe.gob.pe/ pdf/junio2012.pdf

2. Artículo IX de los Principios Generales, Título Preliminar, Código Penal. Publicado Decreto Legislativo № 635 (08/04/1991)

3. Wikipedia. [Internet]. San Francisco: Fundación Wikimedia Inc.; Fecha de acceso [29/05/2012]. Pena [01 pantalla]. http:// es.wikipedia.org/wiki /pena

4. Artículo II del Título Preliminar del Código de Ejecución Penal. Publicado Decreto Legislativo $\quad N o 654$ (03/01/1991)

5. Cuarta Disposición Final de la Constitución Política del Perú. Congreso Constituyente Democrático. 1983.

6. Artículo 10 del Pacto Internacional de Derechos Civiles y Políticos. Aprobado en el Perú por Decreto Ley $N^{\circ} 22128$ (28/03/1978).

Correo electrónico: soria_ius@hotmail.com 